\title{
Intake Estimation of Phytochemicals in a French Well-Balanced Diet
}

\author{
Marie-Josèphe Amiot ${ }^{1, * \mathbb{C}}$, Christian Latgé ${ }^{2}$, Laurence Plumey ${ }^{3}$ and Sylvie Raynal ${ }^{4}$ \\ 1 INRAE, MoISA, University of Montpellier, CIHEAM-IAMM, CIRAD, Institut Agro-Montpellier SupAgro, \\ IRD, Campus La Gaillarde, 2 Place Pierre Viala, 34000 Montpellier, France \\ 2 Pierre Fabre Laboratories, Langlade-3 Avenue Hubert Curien-BP 13 562, CEDEX 1, 31035 Toulouse, France; \\ christian.latge@pierre-fabre.com \\ 3 NUTRITION CO\&CO, 11 Avenue des Vignes, 92210 St Cloud, France; laurence.plumey@free.fr \\ 4 Naturactive, Pierre Fabre Laboratories, 29 Avenue du Sidobre, 81106 Castres, France; \\ sylvie.raynal@pierre-fabre.com \\ * Correspondence: marie-josephe.amiot-carlin@inrae.fr; Tel.: +33-(0)4-99-61-22-16
}

check for

updates

Citation: Amiot, M.-J.; Latgé, C.;

Plumey, L.; Raynal, S. Intake

Estimation of Phytochemicals in a

French Well-Balanced Diet. Nutrients

2021, 13, 3628. https://doi.org/

$10.3390 /$ nu13103628

Academic Editors:

Laura Domínguez Díaz,

Montaña Cámara

and Virginia Fernández-Ruiz

Received: 30 September 2021

Accepted: 14 October 2021

Published: 16 October 2021

Publisher's Note: MDPI stays neutral with regard to jurisdictional claims in published maps and institutional affiliations.

Copyright: (C) 2021 by the authors. Licensee MDPI, Basel, Switzerland. This article is an open access article distributed under the terms and conditions of the Creative Commons Attribution (CC BY) license (https:/ / creativecommons.org/licenses/by/ $4.0 /)$.
Abstract: Phytochemicals contribute to the health benefits of plant-rich diets, notably through their antioxidant and anti-inflammatory effects. However, recommended daily amounts of the main dietary phytochemicals remain undetermined. We aimed to estimate the amounts of phytochemicals in a well-balanced diet. A modelled diet was created, containing dietary reference intakes for adults in France. Two one-week menus (summer and winter) were devised to reflect typical intakes of plant-based foods. Existing databases were used to estimate daily phytochemical content for seven phytochemical families: phenolic acids, flavonoids (except anthocyanins), anthocyanins, tannins, organosulfur compounds, carotenoids, and caffeine. The summer and winter menus provided 1607 and $1441 \mathrm{mg} /$ day, respectively, of total polyphenols (phenolic acids, flavonoids, anthocyanins, and tannins), the difference being driven by reduced anthocyanin intake in winter. Phenolic acids, flavonoids (including anthocyanins), and tannins accounted for approximately 50\%, 25\%, and 25\% of total polyphenols, respectively. Dietary carotenoid and organosulfur compound content was estimated to be approximately 17 and $70 \mathrm{mg} /$ day, respectively, in both seasons. Finally, both menus provided approximately $110 \mathrm{mg}$ /day of caffeine, exclusively from tea and coffee. Our work supports ongoing efforts to define phytochemical insufficiency states that may occur in individuals with unbalanced diets and related disease risk factors.

Keywords: Mediterranean diet; phytonutrients; dietary recommendations; healthy diet; polyphenols; flavonoids; carotenoids; organosulfur; caffeine

\section{Introduction}

A healthy diet is considered to be one that provides adequate calories and nutrients to meet an individual's needs for energy, growth, and repair, and to prevent diet-related non-communicable diseases. A diverse range of foods from several different food groups should be included. Plant-derived foods, such as whole grains, fruits, vegetables, nuts, and seeds, form an essential part of healthy diets.

Healthy, plant-rich diets (including Mediterranean-type or DASH (Dietary Approaches to Stop Hypertension) diets) have been reported to cover all of the macro- and micronutrients considered essential to health [1]. They are particularly rich in monounsaturated and polyunsaturated fatty acids and antioxidants, which regulate lipid and glucose metabolism, counteract oxidative stress, reduce inflammation, and support endothelial function [2]. Adherence to a Mediterranean diet has been associated with comparatively low rates of cardiovascular and cerebrovascular disease, diabetes, cancer, and cognitive decline [3-8].

Additionally, numerous studies have described the health benefits of foods rich in phytochemicals, also named bioactive compounds or phytonutrients or phytomicroconstituents, which are bioactive secondary metabolites found in plants, and in foods, drinks, 
and condiments derived from them $[9,10]$. Phytochemicals are chemically diverse compounds that can be classified into distinct families: polyphenols (phenolic acids, flavonoids (including anthocyanins), and tannins), carotenoids (for example, beta-carotene, lycopene, lutein, and zeaxanthin), organosulfur compounds (for example, isothiocyanates, indoles, allyl sulfur compounds, and sulforaphane), and phytosterols (for example, sitosterol, campesterol, stigmasterol, sitostanol, campestanol, and stigmastanol) [11]. Table 1 lists examples of foods that are high, medium, or low in each of these phytochemical families, although it must be noted that harvesting, processing, storage, and cooking can reduce the phytochemical content of food.

Table 1. Foods and drinks considered to have high, medium, and low levels of different families of phytochemicals [11]. Reference ranges describing high, medium, and low phytochemical levels differ between phytochemical families, and are therefore shown alongside each family above the list of foods. The units of measurement for these reference ranges are mg per $100 \mathrm{~g}$ (for foods) or mg per $100 \mathrm{~mL}$ (for drinks).

\begin{tabular}{|c|c|c|}
\hline Phytochemical Class & High & Medium \\
\hline \multirow[t]{2}{*}{ Phenolic acids } & $100-650$ & $45-100$ \\
\hline & $\begin{array}{l}\text { Flax and sunflower seeds, yams, } \\
\text { red chicory, filter coffee, } \\
\text { artichokes, prunes, mushrooms, } \\
\text { endive, mangos, Jerusalem } \\
\text { artichokes, raspberries }\end{array}$ & $\begin{array}{c}\text { Cherries, chia seeds, dark } \\
\text { chocolate ( } 70-85 \% \text { cocoa), } \\
\text { pineapple, wholegrain wheat, } \\
\text { flageolet beans, white beans, } \\
\text { lentils, split peas }\end{array}$ \\
\hline \multirow[t]{2}{*}{$\begin{array}{l}\text { Flavonoids (except } \\
\text { anthocyanins) }\end{array}$} & $50-250$ & $10-50$ \\
\hline & $\begin{array}{l}\text { Dark chocolate (70-85\% cocoa), } \\
\text { parsley, black tea, dill, shallots, } \\
\text { fennel, green tea, red chicory, } \\
\text { rocket, mint, grapefruit, } \\
\text { cress, thyme }\end{array}$ & $\begin{array}{l}\text { Red wine, blackberries, oranges, } \\
\text { soy, kale, lemons, chia seeds, } \\
\text { cranberries, onions, black grapes, } \\
\text { artichokes, chives, asparagus, } \\
\text { mandarins, blueberries, pecan } \\
\text { nuts, buckwheat, cherries, olives, } \\
\text { blackcurrants, turnips, pistachio } \\
\text { nuts, broccoli, spinach, apricots, } \\
\text { prunes, endive }\end{array}$ \\
\hline
\end{tabular}

\begin{tabular}{|c|c|c|c|}
\hline Anthocyanins & $45-210$ & $10-45$ & $1-10$ \\
\hline & $\begin{array}{l}\text { Red cabbage, blueberries, } \\
\text { blackcurrants, red chicory, } \\
\text { blackberries, aubergines } \\
\text { (eggplants), cranberries, red } \\
\text { radishes, raspberries }\end{array}$ & $\begin{array}{l}\text { Currant berries, cherries, } \\
\text { strawberries, red wine, pecan nuts }\end{array}$ & $\begin{array}{c}\text { Pistachio nuts, hazelnuts, red beans, prunes, } \\
\text { walnuts, almonds, apples, nectarines, pears, } \\
\text { peaches, dates }\end{array}$ \\
\hline \multirow[t]{2}{*}{ Tannins } & $100-600$ & $10-100$ & $1-10$ \\
\hline & $\begin{array}{l}\text { Blackcurrants, red beans, } \\
\text { hazelnuts, pecan nuts, cranberries, } \\
\text { pistachios, red cabbage, plums, } \\
\text { blueberries, almonds, peanuts, } \\
\text { strawberries, apples }\end{array}$ & $\begin{array}{l}\text { White and black grapes, peach, } \\
\text { walnuts, currant berries, pears, } \\
\text { apricots, raspberries, nectarines, } \\
\text { red wine, blackberries, cherries, } \\
\text { dates, mangos }\end{array}$ & $\begin{array}{l}\text { Buckwheat, green tea, quinces, black tea, } \\
\text { bananas, kiwifruit, cashew nuts }\end{array}$ \\
\hline \multirow[t]{2}{*}{ Carotenoids } & $5-20$ & $2.5-5$ & $1-2.5$ \\
\hline & $\begin{array}{l}\text { Spinach, carrots, parsley, kale, red } \\
\text { chicory, basil, squash, yams, cress, } \\
\text { lettuce, coriander (cilantro) }\end{array}$ & $\begin{array}{l}\text { Arugula, watermelon, pistachio } \\
\text { nuts, chives, leeks, thyme, } \\
\text { tomatoes, persimmons, } \\
\text { olives, peas }\end{array}$ & $\begin{array}{l}\text { Red bell peppers (capsicum), grapefruit, } \\
\text { apricots, melon, Brussels sprouts, broccoli, } \\
\text { fennel, asparagus, flat beans, red cabbage, } \\
\text { avocados }\end{array}$ \\
\hline \multirow[t]{2}{*}{ Sulfur compounds } & $>1000$ & $100-250$ & $10-100$ \\
\hline & Onions, leeks & $\begin{array}{l}\text { Brussels sprouts, garlic, black } \\
\text { radishes, kale }\end{array}$ & $\begin{array}{l}\text { Red radishes, red cabbage, broccoli, green } \\
\text { cabbage, white cabbage, cauliflower }\end{array}$ \\
\hline
\end{tabular}

Watermelon, red beans, cashew nuts, walnuts, coriander (cilantro), potatoes, peaches, carrots, black tea, broccoli, dates, basil, apples, white rice, blackcurrants, quinces, green tea, nectarines, peaches, red wine, red bell peppers (capsicum), pears, strawberries, apricots, turnips, grapefruit, cauliflower

$1-10$

Peaches, apples, almonds, figs, raspberries, green bell peppers (capsicum), Brussels sprouts, strawberries, bananas, nectarines, pears, coriander (cilantro), blackcurrants, hazelnuts, flat beans, flageolet beans, white beans, lentils, split peas, green beans, celery, garlic, leeks, white grapes, lettuce, kiwifruit, black radishes, chickpeas, quinces, persimmons, mangos, yellow bell peppers (capsicum), squash, potatoes, tomatoes, courgettes, flax seeds, cashew nuts, white cabbage, cauliflower, watermelon 
Table 1. Cont.

\begin{tabular}{cccc}
\hline Phytochemical Class & High & Medium & Low \\
\hline Caffeine & $50-100$ & $10-50$ & $<10$ \\
\hline Phytosterols & Espresso, filter coffee & Energy drinks, black tea, green tea & Cola drinks \\
\hline & $>200$ & $50-200$ & $3-50$ \\
\hline & $\begin{array}{c}\text { Vegetable oils (corn, } \\
\text { sunflower, soybean) }\end{array}$ & $\begin{array}{c}\text { Almonds, peanuts, corn (maize), } \\
\text { oats, wheat }\end{array}$ & $\begin{array}{c}\text { Cauliflower, broccoli, carrots, tomatoes, apples, } \\
\text { bananas, grapes, oranges }\end{array}$ \\
\hline
\end{tabular}

Dietary polyphenols are present in numerous plant-derived foods and beverages, their quantities differing according to the plant species, varietal, environmental factors (for example, climate and soil), and cultural practices. This family includes phenolic acids (for example, hydroxybenzoic and hydroxycinnamic acids), flavonoids, and tannins. Flavonoids, such as flavones, flavonols, flavanones, and flavanes (also called flavanols or catechins) are present in high amounts in dark chocolate (70-85\% cocoa), black and green teas, herbs (for example, parsley, dill, shallots, fennel, mint, and thyme), salad vegetables (for example, red chicory, rocket, and cress), and grapefruit. Anthocyanins, a subtype of flavonoids, are water-soluble pigments that contribute to the red, purple, or blue color of plants and products derived from them. Thus, they are found in high quantities in berries (for example, blueberries, blackcurrants, blackberries, cranberries, and raspberries) and in red varieties of cabbage, chicory, and radish. Tannins are grouped into two main categories, namely hydrolyzable tannins (gallotannins and ellagitannins) and non-hydrolyzable, or condensed tannins (proanthocyanidins). Tannins are found in high quantities in berries (for example, blackcurrants, cranberries, blueberries, and strawberries), nuts (for example, hazelnuts, pecans, pistachios, almonds, and peanuts), stone fruits (for example, plums), red beans, and red cabbage.

Leafy greens and orange vegetables are the richest sources of carotenoids. The most abundant carotenoid is beta-carotene, which is hydrolyzed in vivo to vitamin A (hence its alternative name, provitamin A). However, other carotenoids, such as lycopene (a red pigment present in red tomatoes and grapefruit), lutein (found in green vegetables such as spinach and lettuce), and zeaxanthin (found in corn (maize)) are not metabolized to vitamin A.

Dietary sulfur compounds are divided into two classes: allyl sulfur compounds (for example, alliin), which are abundant in alliaceous vegetables, such as onions (Allium cepa) and garlic (Allium sativum); and glucosinolates, which are found in cruciferous vegetables, especially broccoli. During culinary processing and after ingestion, allyl sulfur compounds and glucosinolates undergo transformation to highly bioactive compounds (diallyl mono-, di- or tri-sulfides, sulforaphanes, and isothiocyanates) that have antioxidant and detoxifying properties [12].

A phytochemical index (PI), based on $24 \mathrm{~h}$ intake recall, has been proposed for use in epidemiological studies of diseases in which diet is a causative factor [13]. The PI is the percentage of dietary calories derived from foods that are rich in phytochemicals. Diets with a higher PI have been associated with a lower prevalence of cardiometabolic disorders, including abdominal obesity, hyperglycemia, hypertension, hypertriglyceridemia, and metabolic syndrome [13]. Although the PI is a useful global indicator, it does not consider the amounts of individual phytochemicals or phytochemical families that are present in a healthy diet; indeed, there is currently no sufficiently sophisticated estimation method that allows dietary phytochemical content to be readily quantified in a clinical setting. We therefore undertook a study to determine levels of different phytochemicals in a well-balanced French diet, in order to inform and support public health objectives and recommendations in France. 


\section{Materials and Methods}

We designed two typical weekly seasonal menus, one for summer and one for winter, included plant-based foods commonly found in current French diets (see Tables S1 and S2 in the Supplementary Materials). The menus were consistent with the current recommendations of the French National Agency for Food, Environmental and Occupational Health and Safety (ANSES; Agence Nationale de Sécurité Sanitaire Alimentation, Environnement, Travail) [14] and with the scientific literature [15]. Additionally, the menus were designed to include all essential macro- and micronutrients, and to account for seasonal variations in the availability of plant foods. We then prepared tables of the phytochemical content of each food, and used these to estimate the expected phytochemical intake per day for each menu.

Portion sizes were determined for each food category in accordance with French dietary habits, guidelines from the Groupe d'Étude des Marchés en Restauration Collective et Nutrition (GEM-RCN; French Collective Study Group on Catering and Nutrition) [16] and Programme National Nutrition Santé (PNNS; the French National Health Nutrition Programme) [17], and the opinion of the authors.

For each of the menus, the amount of each food category (FC) consumed daily (i.e., FCy, measured in grams) was calculated using the following formula:

$$
\mathrm{FC} y=\mathrm{FF} \times z \times \mathrm{PS}
$$

where FF (frequency factor) is a multiplier reflecting the frequency of intake (FF: Frequency factors $=1$ per day, 0.143 per week, and 0.033 per month), $z$ denotes the total number of servings, and PS is the portion size in grams.

A database of the phytochemical content of 116 plant foods (mainly fruits and vegetables) was created. The phytochemicals of interest were phenolic acids, flavonoids (including anthocyanins, which were considered separately); tannins; organosulfur compounds; carotenoids; and caffeine. The phytochemical content of individual foods was obtained from the US Department of Agriculture for carotenoids and flavonoids (including anthocyanidins) [18-20]; Phenol-Explorer for total polyphenols and phenolic acids [21-23]; and published scientific literature for tannins and organosulfur compounds [24]. Data for organosulfur compounds found in garlic and onion, regrouped in the same category, were also added. Other data were derived from consumption studies, such as the study of the average consumption of fruits and vegetables in France [14], as well as research on phytochemicals reported by Tennant et al. in 2014 [25].

Our analysis focused on phytochemicals with proven health benefits at amounts that can be readily obtained by dietary intake. Thus, we did not include phytosterols, because the beneficial effects of these compounds require a level of intake (for example, $>3 \mathrm{~g} /$ day for phytosterols) that can only be achieved by dietary supplementation. Conversely, caffeine was included as a family in its own right because it accounts for a significant proportion of daily phytochemical intake, has well-documented health benefits, and is routinely included in nutritional recommendations such as those issued by ANSES [14].

Deviations of each phytochemical that result from an aggregation of numerous-level values associated to the variability of plant food products and their consumption frequencies are taken into account in our values. Moreover, some phytochemicals (i.e., carotenoids) supplied by consuming animal-origin foods such as fish, eggs, milk, and meats were not integrated in calculations. Animal food products were included in our menus to balance the caloric intake, but not retained, because their contribution was very low in comparison to that of the plant food products. 


\section{Results}

For each menu, the weekly number of portions, and the estimated daily amounts of each food category, are shown in Table 2 . The estimated daily amounts of phytochemicals associated with each menu are shown in Table 3.

Table 2. Menu analysis, according to the number of portions of each food category consumed per week and the amount (expressed in grams) of each food category consumed per day.

\begin{tabular}{|c|c|c|c|c|c|}
\hline \multirow{2}{*}{ Food Category } & \multirow{2}{*}{ Examples } & \multicolumn{2}{|c|}{ Portions per Week } & \multicolumn{2}{|c|}{ Amounts per Day (g) } \\
\hline & & Summer Menu & Winter Menu & Summer Menu & Winter Menu \\
\hline \multicolumn{6}{|c|}{ Grains, beans, nuts, and seeds } \\
\hline Starchy foods & $\begin{array}{l}\text { Corn, buckwheat, Jerusalem artichokes, oats, } \\
\text { potatoes, quinoa, rice (white and whole), } \\
\text { rye, wheat (refined and whole) }\end{array}$ & 16 & 18 & 274.3 & 308.6 \\
\hline Pulses & $\begin{array}{l}\text { Chickpeas, flageolet beans, lentils, red beans, } \\
\text { split peas, white beans }\end{array}$ & 2 & 2 & 34.3 & 34.3 \\
\hline Nuts and seeds & $\begin{array}{l}\text { Almonds, cashew nuts, chia seeds, coconut, } \\
\text { flax seeds, hazelnuts, macadamia nuts, } \\
\text { peanuts, pecan nuts, pistachio nuts, sesame } \\
\text { seeds, sunflower seeds, walnuts }\end{array}$ & 0 & 1 & 0 & 2.9 \\
\hline \multicolumn{6}{|c|}{ Fruits, vegetables, spices, and herbs } \\
\hline White & $\begin{array}{l}\text { Apples, endive, mushrooms, quinces, } \\
\text { parsnips, pears, salsify, turnips, white grapes }\end{array}$ & 2 & 13 & 35.7 & 232.1 \\
\hline White/green & Celery, fennel, leek, shallots & 2 & 3 & 35.7 & 53.6 \\
\hline Green & $\begin{array}{l}\text { Avocados, asparagus, artichokes, courgettes, } \\
\text { cress, cucumbers, flat beans, green beans, } \\
\text { green bell peppers (capsicum), kiwifruit, } \\
\text { lettuce, olives, peas, rocket, spinach }\end{array}$ & 10 & 7.5 & 178.6 & 133.9 \\
\hline Yellow & $\begin{array}{l}\text { Bananas, lemons, pineapple, yellow bell } \\
\text { peppers (capsicum) }\end{array}$ & 3 & 5 & 53.6 & 89.3 \\
\hline Orange & Carrots, mandarins, oranges, squash, yams & 10 & 6 & 178.6 & 107.2 \\
\hline Red & $\begin{array}{l}\text { Beetroot, cherries, cranberries, redcurrants, } \\
\text { dates, figs, grapefruit, plums, raspberries, } \\
\text { red bell peppers (capsicum), strawberries, } \\
\text { tomatoes, watermelon }\end{array}$ & 13 & 2 & 232.1 & 35.7 \\
\hline Purple & $\begin{array}{l}\text { Plums, blackcurrants, blackberries, } \\
\text { blueberries, eggplants, black grapes, } \\
\text { red chicory }\end{array}$ & 5 & 3 & 89.3 & 53.6 \\
\hline $\begin{array}{l}\text { Cruciferous } \\
\text { vegetables }\end{array}$ & $\begin{array}{l}\text { Brussels sprouts, broccoli, cauliflower, green } \\
\text { cabbage, kale, red cabbage, white cabbage }\end{array}$ & 0 & 2 & 0 & 35.0 \\
\hline Radishes & Black radishes, red radishes & 2 & 0 & 35.0 & 0 \\
\hline Allium spp. & Garlic, onions, chives & 2 & 2 & 5.6 & 5.6 \\
\hline Herbs & $\begin{array}{l}\text { Basil, coriander (cilantro), dill, mint, } \\
\text { parsley, thyme }\end{array}$ & 10 & 9 & 14.3 & 12.9 \\
\hline \multicolumn{6}{|c|}{ Beverages } \\
\hline Coffee (filter) & & 3 & 3 & 85.7 & 85.7 \\
\hline Coffee (espresso) & & 7 & 7 & 60.0 & 60.0 \\
\hline Tea & Black tea, green tea & 4 & 4 & 114.3 & 114.3 \\
\hline Wine & Red wine & 2 & 2 & 34.3 & 34.3 \\
\hline Other & Sodas, energy drinks & 1 & 1 & 28.0 & 28.0 \\
\hline \multicolumn{6}{|c|}{ Plant-derived sweets } \\
\hline Chocolate & Dark chocolate $(70-85 \%$ cocoa) & 7 & 7 & 19.6 & 19.6 \\
\hline
\end{tabular}


Table 3. Quantity of each phytochemical family (expressed in mg/day) provided by the menus, according to food category.

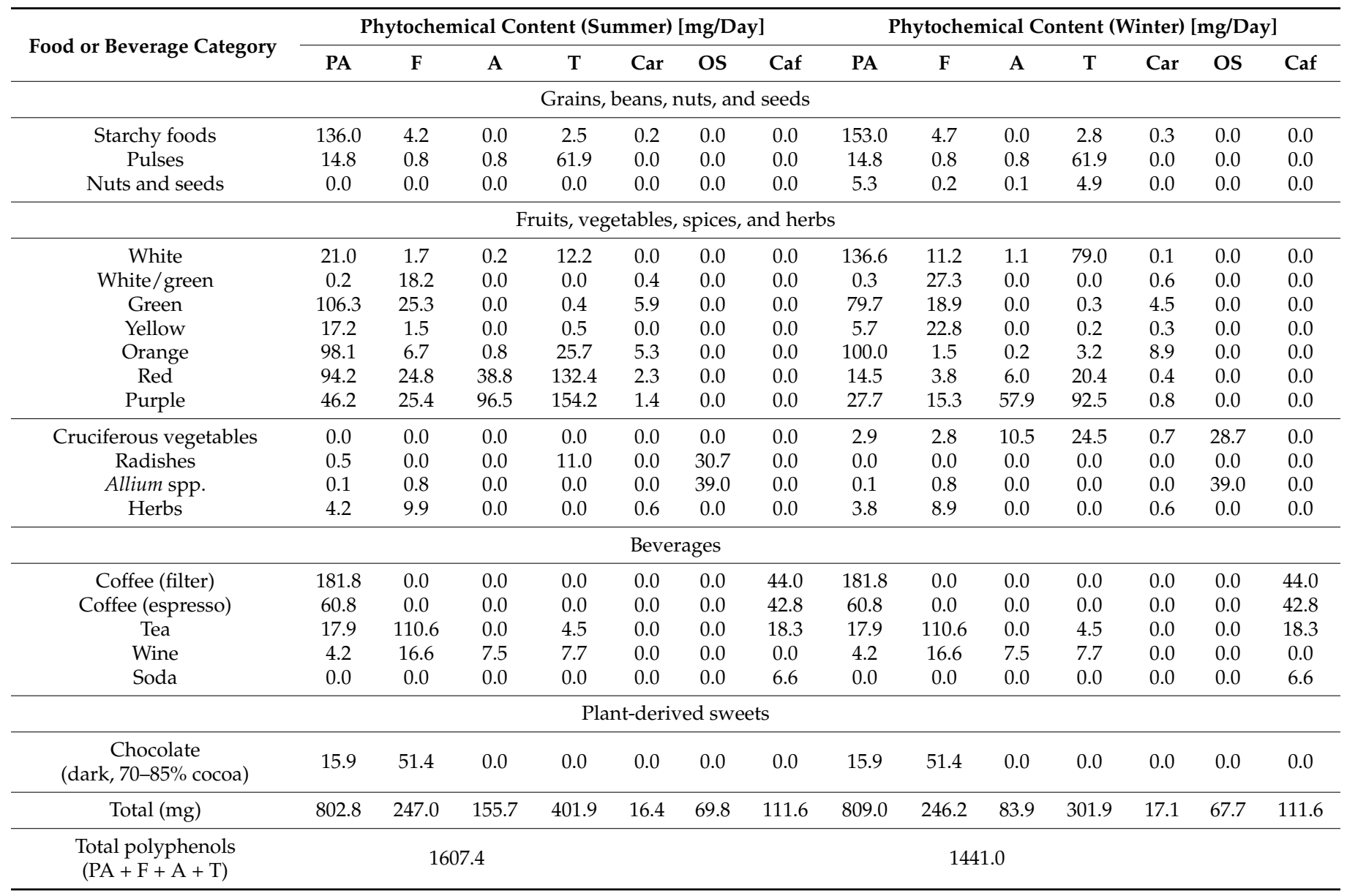

A, anthocyanins; Caf, caffeine; Car, carotenoids; F, flavonoids (except anthocyanins); OS, organosulfur compounds; PA, phenolic acids; $\mathrm{T}$, tannins.

\subsection{Polyphenols}

The summer and winter menus were estimated to provide 1607.4 and $1441.0 \mathrm{mg} /$ day, respectively, of polyphenols. Approximately $50 \%$ of the polyphenol content of each menu was accounted for by phenolic acids ( $800 \mathrm{mg} /$ day), with no difference being observed between menus. Among individual foods and food categories, filter coffee and starchy foods (including cereal grains such as oats, rye, and wheat) were the most important sources of phenolic acids, accounting for approximately $22-23 \%$ and $17-19 \%$, respectively, of estimated total phenolic acids intake. Fruits and vegetables were also found to be important sources of phenolic acids, providing around $350 \mathrm{mg} /$ day.

Flavonoids (including anthocyanins) and tannins were each estimated to account for approximately $25 \%$ of total polyphenols ( $400 \mathrm{mg}$ /day in summer and $300-330 \mathrm{mg} /$ day in winter; Table 3). Seasonal differences were driven by greater consumption of red and purple fruits and vegetables during the warmer months of the year, leading to a higher intake of anthocyanins in summer than in winter. Red and purple fruits and vegetables provided $287 \mathrm{mg}$ / day of tannins in summer (71\% of total daily tannin consumption), but just $113 \mathrm{mg} /$ day in winter (37\% of total daily tannin consumption). Conversely, pulses and white fruits and vegetables accounted for a greater proportion of total tannin intake in winter than in summer ( $46.7 \%$ vs. $18.4 \%$, respectively).

\subsection{Carotenoids}

As shown in Table 3, the carotenoid content of each menu was significantly lower than the polyphenol content on a milligram basis (by a factor of 100 in summer and 84 in winter). However, there was little difference between the daily carotenoid content of the summer 
menu (16.2 mg/day) and the winter menu (17.1 mg/day) due to the year-round availability of foods such as leafy greens, orange fruits and vegetables, and tomatoes. Virtually all of the carotenoid content of both menus was provided by fruits and vegetables, with very little coming from other sources.

\subsection{Organosulfur Compounds}

Estimated intakes of organosulfur compounds were comparable in summer and winter (approximately $70 \mathrm{mg} /$ day), but sources varied between the seasons. In summer, radishes formed an important source of organosulfur compounds, with cruciferous vegetables being important in the winter. Allium spp., such as garlic and onions, were important sources of organosulfur compounds all year round.

\subsection{Caffeine}

Our menus provided $111.6 \mathrm{mg} /$ day of caffeine in both winter and summer, the majority of which was from coffee.

\section{Discussion}

We used public domain data to estimate the daily amounts of phytochemicals, divided into seven families, that would be provided by two one-week seasonal menus that were considered to: (i) represent a healthy diet; and (ii) accurately reflect the seasonal availability of plant foods in France.

The estimated total polyphenol content, calculated as the sum of phenolic acids, flavonoids, anthocyanins, and tannins of each menu was 1607.4 and $1441.0 \mathrm{mg} /$ day in summer and winter, respectively. These values are $20-35 \%$ higher than those found in the French SUVIMAX study [26], but comparable to those in a recent analysis of data from the US National Health and Nutrition Examination Survey (NHANES) [27]. In the latter study, participants had mean total polyphenol intakes of $1656.6 \mathrm{mg} /$ day, although there were significant differences between subgroups defined by age, sex, educational level, and body mass index.

We found coffee and starchy foods to be the most important sources of phenolic acids in our sample diets. Regular coffee drinkers have been shown to have a reduced risk of type 2 diabetes and cardiovascular diseases compared with non-drinkers [28]. Although the benefits of coffee have been assumed to be a result of its caffeine content [28], decaffeinated coffee also appears to provide health benefits [29]. This could be due to the presence of chlorogenic acids, which are not removed by decaffeination; these compounds are responsible for the antioxidant and anti-inflammatory properties of coffee [28]. Starchy foods also contain phenolic acids in significant amounts, with cereal bran being a particularly rich source of ferulic acid [30]. Epidemiological studies have suggested that diets rich in wholegrain cereals have protective effects against cardiovascular disease, type 2 diabetes, and cancer, and are useful in weight management; the latter observation may be attributable to both dietary fiber and phenolic acid content [31]. Consumption of leafy green vegetables, which we also found contributed significantly to phenolic acid intake, has been associated with a significantly reduced risk of type 2 diabetes [32]. This reduction, however, could be due to the presence of other phytochemicals (for example, carotenoids) and dietary fiber.

Our menus provided approximately $400 \mathrm{mg}$ /day of flavonoids (including anthocyanins), a level of intake that was associated in a recent meta-analysis with the maximal reduction in coronary heart disease risk [33]. Among flavonoid subtypes, flavonols and flavones were associated with reduced risks of coronary heart disease, but anthocyanins and flavan-3-ols were found to offer the greatest protection against cardiovascular disease overall [33].

In vitro and animal studies have shown that flavonoids have antioxidant and antiinflammatory properties, and that they can inhibit mutagenesis and carcinogenesis [34]. The potential of anthocyanins to prevent a range of chronic diseases (including obesity, type 2 diabetes, cardiovascular disease, visual disorders, and neuropathies) has also been 
studied [35]. For example, a meta-analysis of 128 randomized controlled trials reported that the consumption of foods rich in anthocyanins was associated with favorable changes in blood pressure and total cholesterol in overweight or obese people [36].

As well as being rich in anthocyanins, red and purple fruits and vegetables are important dietary sources of tannins. The reduced availability (and hence consumption) of these foods in winter contributes to an approximately $25 \%$ reduction in tannin intake during the colder months. This may be particularly relevant to the health of people who are overweight or obese, in whom the consumption of foods rich in ellagitannins (for example, pomegranate, berries, and nuts) has been shown to lower total cholesterol, lowdensity lipoprotein (LDL)-cholesterol, and triglycerides levels, and to reduce diastolic blood pressure [36]. With respect to procyanidins, (condensed tannins), Wallace and colleagues have proposed an intake of $200 \mathrm{mg} /$ day, with an upper limit of $800 \mathrm{mg} /$ day [37]. Tannins have been described as antinutritional factors because of their potential to impair iron bioavailability, and tannin consumption has been linked to the high prevalence of iron deficiency [38].

Overall, however, a diet rich in a diverse range of polyphenols may be recommended as an effective nutritional strategy to improve the health of patients with metabolic syndrome, with potentially beneficial effects on body fat, blood pressure, dyslipidemia, and insulin resistance, and reductions in oxidative stress, inflammation, and vascular dysfunction [39].

The antioxidant (singlet oxygen quenching and free radical scavenging) and antiinflammatory properties of carotenoids are mediated via nuclear factor kappa B (NF- $\mathrm{kB}$ ) receptors, which modulate cytokine and chemokine production [40]. Higher intakes of carotenoids, particularly beta-carotene and lycopene, have been shown to be inversely associated with a lower incidence risk of coronary heart disease and stroke [41]; furthermore, blood concentrations of carotenoids and cryptoxanthin are inversely associated with the incidence of cardiovascular disease, total cancer, and all-cause mortality [41]. Additionally, consumption of carotenoid-rich foods may reduce the risk of metabolic syndrome [42]. In the eye, lutein (present in leafy green vegetables), zeaxanthin, and meso-zeaxanthin (present in corn (maize)) accumulate in the macula; their beneficial effects on vision and eye health are due to protective effects against the oxidative damage caused by ultraviolet light [43]. Daily intakes of $6 \mathrm{mg}$ of lutein and $18 \mathrm{mg}$ of lycopene have been recommended, with upper limits of 60 and $50 \mathrm{mg} /$ day, respectively [37].

Cruciferous vegetables are a source of glucosinolates, which are converted in vivo to sulforaphane; this bioactive metabolite has been found, in in vitro and animal studies, to have anticarcinogenic effects [44]. Allium plant species (for example, onion and garlic) are a source of S-alk(en)yl-L-cysteine sulfoxides. Allium spp. may provide some protection against cancer, cardiovascular disease, metabolic disorders, and bone disease, due to their antioxidant, anti-inflammatory, and lipid-lowering properties $[45,46]$.

Our menus delivered identical daily amounts of caffeine regardless of season. In France, tea and coffee are the two major dietary sources of caffeine. At one end of the scale, brewed black tea provides approximately $20 \mathrm{mg}$ caffeine per $100 \mathrm{~mL}$, while, at the other, espresso coffee provides approximately $75 \mathrm{mg}$ caffeine per $100 \mathrm{~mL}$ [47]. However, the caffeine content of prepared coffee beverages is known to vary considerably (58-259 mg per $100 \mathrm{~mL}$ ), with espresso coffees typically containing less caffeine than brewed coffees [48], and there is therefore likely to be wide inter- and intra-individual variation in caffeine intake among French people. It is also important to recognize that, in recent decades, energy drinks and sodas have become significant sources of caffeine.

Caffeine, among other properties, has been reported to increase energy expenditure [49], and its consumption may have measurable metabolic effects in at least some individuals. In a meta-analysis published in 2011, caffeine and catechins were found to synergistically augment fat oxidation [50]. Rigorous reviews have concluded that the consumption of up to $400 \mathrm{mg} /$ day of caffeine is not associated with adverse effects in healthy adults [51-53]. An upper limit of $300 \mathrm{mg} /$ day has been proposed for pregnant women [51]. 
There are limitations to the type of analysis that we have presented here. First, we only considered 116 food items. Second, a major consideration is that agronomic practices (for example, variety, irrigation, fertilization, and harvesting date) and methods of food storage and preparation can significantly modify the phytochemical content of plant foods [54-57]. A sensitivity study should be carried out in the future with the high, medium, and low values of phytochemicals. We did not take this into account, due to a lack of robust scientific data in the USDA and Phenol-Explorer databases on these effects. The extent to which processing affects nutrient content varies between foods, and it was therefore impossible to apply a universal multiplier or other factor to adjust for food preparation. Indeed, while cooking food generally results in the loss of water-soluble, oxidizable, and heat-sensitive phytochemicals, it can also lead to an improvement in the assimilation of others, such as carotenoids [58].

\section{Conclusions}

Our study estimates the levels of different phytochemicals that are present in a wellbalanced French diet (i.e., one meeting current guidelines on macro- and micronutrient requirements) in adults. This estimation constitutes the first step to addressing, in the future, adequate intakes to support health benefits. Our findings indicate that consuming a diverse range of plant foods provides a broad spectrum of phytochemicals in both summer and winter, with estimated intakes of each phytochemical family being generally comparable between the seasons. Further research linking dietary phytochemical intake to health outcomes would allow existing approaches to PI calculation to be refined and improved. We believe our work will help dietitians and nutritionists to identify gaps between observed and target phytochemical intake in adults in France, and to recommend personalized nutritional strategies for maintaining good health. We plan to carry out further work to deliver personalized dietary solutions, taking into account individual specificities, such allergies, and food intolerances and preferences.

Supplementary Materials: The following are available online at https:/ /www.mdpi.com/article/10 .3390/nu13103628/s1: Table S1: Summer menu; Table S2: Winter menu.

Author Contributions: Conceptualization, M.-J.A., C.L. and S.R.; Methodology, M.-J.A., C.L. and S.R.; Formal Analysis, C.L. and S.R.; Validation, M.-J.A.; Writing-Original Draft Preparation, M.-J.A.; Writing-Review \& Editing, M.-J.A., C.L., L.P. and S.R. All authors have read and agreed to the published version of the manuscript.

Funding: This research received no external funding.

Institutional Review Board Statement: Not applicable.

Informed Consent Statement: Not applicable.

Data Availability Statement: All scientific data calculated in the course of this study, and presented in this publication, are available from Christian Latgé and Sylvie Raynal upon reasonable request. All requests should be sent to: sylvie.raynal@pierre-fabre.com.

Acknowledgments: We would like to thank Richard Crampton of Springer Healthcare Communications who edited and formatted the manuscript for publication. This editorial assistance was funded by Pierre Fabre Laboratories, France. We are also grateful to Emilie Ondet, publication manager at Pierre Fabre, who ensured the follow-up of the paper's redaction and communication between the authors and the medical writer.

Conflicts of Interest: M-J. Amiot and L. Plumey have acted as consultants for, and as expert witnesses on behalf of, Pierre Fabre Laboratories, France. C. Latgé and S. Raynal are employees of Pierre Fabre Laboratories, France. 


\section{References}

1. Nissensohn, M.; Román-Viñas, B.; Sánchez-Villegas, A.; Piscopo, S.; Serra-Majem, L. The Effect of the Mediterranean Diet on Hypertension: A Systematic Review and Meta-Analysis. J. Nutr. Educ. Behav. 2016, 48, 42-53. [CrossRef] [PubMed]

2. Korakas, E.; Dimitriadis, G.; Raptis, A.; Lambadiari, V. Dietary Composition and Cardiovascular Risk: A Mediator or a Bystander? Nutrients 2018, 10, 1912. [CrossRef]

3. Esposito, K.; Maiorino, M.I.; Bellastella, G.; Chiodini, P.; Panagiotakos, D.; Giugliano, D. A journey into a Mediterranean diet and type 2 diabetes: A systematic review with meta-analyses. BMJ Open 2015, 5, e008222. [CrossRef] [PubMed]

4. Jannasch, F.; Kröger, J.; Schulze, M.B. Dietary Patterns and Type 2 Diabetes: A Systematic Literature Review and Meta-Analysis of Prospective Studies. J. Nutr. 2017, 147, 1174-1182. [CrossRef]

5. Loughrey, D.G.; Lavecchia, S.; Brennan, S.; Lawlor, B.A.; Kelly, M.E. The Impact of the Mediterranean Diet on the Cognitive Functioning of Healthy Older Adults: A Systematic Review and Meta-Analysis. Adv. Nutr. 2017, 8, 571-586. [CrossRef] [PubMed]

6. Petersson, S.D.; Philippou, E. Mediterranean Diet, Cognitive Function, and Dementia: A Systematic Review of the Evidence. Adv. Nutr. 2016, 7, 889-904. [CrossRef] [PubMed]

7. Rosato, V.; Temple, N.J.; La Vecchia, C.; Castellan, G.; Tavani, A.; Guercio, V. Mediterranean diet and cardiovascular disease: A systematic review and meta-analysis of observational studies. Eur. J. Nutr. 2019, 58, 173-191. [CrossRef]

8. Schwingshackl, L.; Schwedhelm, C.; Galbete, C.; Hoffmann, G. Adherence to Mediterranean Diet and Risk of Cancer: An Updated Systematic Review and Meta-Analysis. Nutrients 2017, 9, 1063. [CrossRef]

9. Fraga, C.G.; Croft, K.D.; Kennedy, D.O.; Tomás-Barberán, F.A. The effects of polyphenols and other bioactives on human health. Food Funct. 2019, 10, 514-528. [CrossRef]

10. Serafini, M.; Peluso, I. Functional Foods for Health: The Interrelated Antioxidant and Anti-Inflammatory Role of Fruits, Vegetables, Herbs, Spices and Cocoa in Humans. Curr. Pharm. Des. 2016, 22, 6701-6715. [CrossRef]

11. Tolve, R.; Cela, N.; Condelli, N.; Di Cairano, M.; Caruso, M.C.; Galgano, F. Microencapsulation as a Tool for the Formulation of Functional Foods: The Phytosterols' Case Study. Foods 2020, 9, 470. [CrossRef]

12. Miękus, N.; Marszałek, K.; Podlacha, M.; Iqbal, A.; Puchalski, C.; Świergiel, A.H. Health Benefits of Plant-Derived Sulfur Compounds, Glucosinolates, and Organosulfur Compounds. Molecules 2020, 25, 3804. [CrossRef]

13. Kim, M.; Park, K. Association between phytochemical index and metabolic syndrome. Nutr. Res. Pract. 2020, $14,252-261$. [CrossRef]

14. Agence Nationale de Sécurité Sanitaire Alimentation. RAPPORT de l'Anses Relatif à l'Actualisation des Repères du PNNS: Étude des Relations Entre Consommation de Groupes d'Aliments et Risque de Maladies Chroniques Non Transmissibles. November 2016. Available online: https:/ / www.researchgate.net/publication/312665902_Actualisation_des_reperes_du_PNNS_ etude_des_relations_entre_consommation_de_groupes_d $\backslash \mathrm{T} 1 \backslash$ textquoterightaliments_et_risque_de_maladies_chroniques_ non_transmissibles (accessed on 1 August 2021).

15. Estruch, R.; Ros, E.; Salas-Salvadó, J.; Covas, M.I.; Corella, D.; Arós, F.; Gómez-Gracia, E.; Ruiz-Gutiérrez, V.; Fiol, M.; Lapetra, J.; et al. Primary Prevention of Cardiovascular Disease with a Mediterranean Diet Supplemented with Extra-Virgin Olive Oil or Nuts. N. Engl. J. Med. 2018, 378, e34. [CrossRef]

16. Groupe d'Etude des Marches de Restauration Collective et Nutrition (GEM-RCN). Recommandation Nutrition. Available online: https:/ / www.economie.gouv.fr/files/directions_services/daj/marches_publics/oeap/gem/nutrition/nutrition.pdf (accessed on 1 September 2021).

17. Chaltiel, D.; Adjibade, M.; Deschamps, V.; Touvier, M.; Hercberg, S.; Julia, C.; Kesse-Guyot, E. Programme National Nutrition Santé-Guidelines score 2 (PNNS-GS2): Development and validation of a diet quality score reflecting the 2017 French dietary guidelines. Br. J. Nutr. 2019, 122, 331-342. [CrossRef] [PubMed]

18. US Department of Agriculture (USDA). USDA Database for the Proanthocyanidin Content of Selected Foods, Release 2. 2015. Available online: https:/ / data.nal.usda.gov/dataset/usda-database-proanthocyanidin-content-selected-foods-release-2-2015 (accessed on 1 September 2021).

19. US Department of Agriculture (USDA). USDA Database for the Flavonoid Content of Selected Foods. Release 3.2. November 2015. Available online: https:/ / data.nal.usda.gov/dataset/usda-database-flavonoid-content-selected-foods-release-32-november2015 (accessed on 1 September 2021).

20. US Department of Agriculture (USDA). USDA Branded Food Products Database. Available online: https://data.nal.usda.gov/ dataset/usda-branded-food-products-database (accessed on 1 September 2021).

21. Rothwell, J.A.; Pérez-Jiménez, J.; Neveu, V.; Medina-Ramon, A.; M’Hiri, N.; Garcia Lobato, P.; Manach, C.; Knox, K.; Eisner, R.; Wishart, D.; et al. Phenol-Explorer 3.0: A major update of the Phenol-Explorer database to incorporate data on the effects of food processing on polyphenol content. Database 2013, 2013, bat070. [CrossRef] [PubMed]

22. Neveu, V.; Perez-Jiménez, J.; Vos, F.; Crespy, V.; du Chaffaut, L.; Mennen, L.; Knox, C.; Eisner, R.; Cruz, J.; Wishart, D.; et al. Phenol-Explorer: An online comprehensive database on polyphenol contents in foods. Database 2010, 2010, bap024. [CrossRef] [PubMed]

23. Phenol-Explorer. Database on Polyphenol Content in Foods. Available online: http://phenol-explorer.eu/foods (accessed on 1 September 2021).

24. McNaughton, S.A.; Marks, G.C. Development of a food composition database for the estimation of dietary intakes of glucosinolates, the biologically active constituents of cruciferous vegetables. Br. J. Nutr. 2003, 90, 687-697. [CrossRef] 
25. Tennant, D.R.; Davidson, J.; Day, A.J. Phytonutrient intakes in relation to European fruit and vegetable consumption patterns observed in different food surveys. Br. J. Nutr. 2014, 112, 1214-1225. [CrossRef]

26. Pérez-Jiménez, J.; Fezeu, L.; Touvier, M.; Arnault, N.; Manach, C.; Hercberg, S.; Galan, P.; Scalbert, A. Dietary intake of 337 polyphenols in French adults. Am. J. Clin. Nutr. 2011, 93, 1220-1228. [CrossRef] [PubMed]

27. Huang, Q.; Braffett, B.H.; Simmens, S.J.; Young, H.A.; Ogden, C.L. Dietary Polyphenol Intake in US Adults and 10-Year Trends: 2007-2016. J. Acad. Nutr. Diet. 2020, 120, 1821-1833. [CrossRef]

28. O'Keefe, J.H.; Bhatti, S.K.; Patil, H.R.; DiNicolantonio, J.J.; Lucan, S.C.; Lavie, C.J. Effects of habitual coffee consumption on cardiometabolic disease, cardiovascular health, and all-cause mortality. J. Am. Coll. Cardiol. 2013, 62, 1043-1051. [CrossRef] [PubMed]

29. Sinha, R.; Cross, A.J.; Daniel, C.R.; Graubard, B.I.; Wu, J.W.; Hollenbeck, A.R.; Gunter, M.J.; Park, Y.; Freedman, N.D. Caffeinated and decaffeinated coffee and tea intakes and risk of colorectal cancer in a large prospective study. Am. J. Clin. Nutr. 2012, 96, 374-381. [CrossRef]

30. Călinoiu, L.F.; Vodnar, D.C. Whole Grains and Phenolic Acids: A Review on Bioactivity, Functionality, Health Benefits and Bioavailability. Nutrients 2018, 10, 1615. [CrossRef]

31. Seal, C.J.; Brownlee, I.A. Whole-grain foods and chronic disease: Evidence from epidemiological and intervention studies. Proc. Nutr. Soc. 2015, 74, 313-319. [CrossRef] [PubMed]

32. Li, M.; Fan, Y.; Zhang, X.; Hou, W.; Tang, Z. Fruit and vegetable intake and risk of type 2 diabetes mellitus: Meta-analysis of prospective cohort studies. BMJ Open 2014, 4, e005497. [CrossRef] [PubMed]

33. Micek, A.; Godos, J.; Del Rio, D.; Galvano, F.; Grosso, G. Dietary Flavonoids and Cardiovascular Disease: A Comprehensive Dose-Response Meta-Analysis. Mol. Nutr. Food Res. 2021, 65, e2001019. [CrossRef]

34. Panche, A.N.; Diwan, A.D.; Chandra, S.R. Flavonoids: An overview. J. Nutr. Sci. 2016, 5, e47. [CrossRef]

35. Khoo, H.E.; Azlan, A.; Tang, S.T.; Lim, S.M. Anthocyanidins and anthocyanins: Colored pigments as food, pharmaceutical ingredients, and the potential health benefits. Food Nutr. Res. 2017, 61, 1361779. [CrossRef]

36. García-Conesa, M.T.; Chambers, K.; Combet, E.; Pinto, P.; Garcia-Aloy, M.; Andrés-Lacueva, C.; de Pascual-Teresa, S.; Mena, P.; Konic Ristic, A.; Hollands, W.J.; et al. Meta-Analysis of the Effects of Foods and Derived Products Containing Ellagitannins and Anthocyanins on Cardiometabolic Biomarkers: Analysis of Factors Influencing Variability of the Individual Responses. Int. J. Mol. Sci. 2018, 19, 694. [CrossRef] [PubMed]

37. Wallace, T.C.; Bailey, R.L.; Blumberg, J.B.; Burton-Freeman, B.; Chen, C.O.; Crowe-White, K.M.; Drewnowski, A.; Hooshmand, S.; Johnson, E.; Lewis, R.; et al. Fruits, vegetables, and health: A comprehensive narrative, umbrella review of the science and recommendations for enhanced public policy to improve intake. Crit. Rev. Food Sci. Nutr. 2020, 60, 2174-2211. [CrossRef]

38. Delimont, N.M.; Haub, M.D.; Lindshield, B.L. The Impact of Tannin Consumption on Iron Bioavailability and Status: A Narrative Review. Curr. Dev. Nutr. 2017, 1, 1-12. [CrossRef]

39. Amiot, M.J.; Riva, C.; Vinet, A. Effects of dietary polyphenols on metabolic syndrome features in humans: A systematic review. Obes. Rev. 2016, 17, 573-586. [CrossRef]

40. Gouranton, E.; Thabuis, C.; Riollet, C.; Malezet-Desmoulins, C.; El Yazidi, C.; Amiot, M.J.; Borel, P.; Landrier, J.F. Lycopene inhibits proinflammatory cytokine and chemokine expression in adipose tissue. J. Nutr. Biochem. 2011, 22, 642-648. [CrossRef] [PubMed]

41. Aune, D.; Keum, N.; Giovannucci, E.; Fadnes, L.T.; Boffetta, P.; Greenwood, D.C.; Tonstad, S.; Vatten, L.J.; Riboli, E.; Norat, T. Dietary intake and blood concentrations of antioxidants and the risk of cardiovascular disease, total cancer, and all-cause mortality: A systematic review and dose-response meta-analysis of prospective studies. Am. J. Clin. Nutr. 2018, 108, 1069-1091. [CrossRef]

42. Goncalves, A.; Amiot, M.J. Fat-soluble micronutrients and metabolic syndrome. Curr. Opin. Clin. Nutr. Metab. Care 2017, 20, 492-497. [CrossRef] [PubMed]

43. Bernstein, P.S.; Li, B.; Vachali, P.P.; Gorusupudi, A.; Shyam, R.; Henriksen, B.S.; Nolan, J.M. Lutein, zeaxanthin, and mesozeaxanthin: The basic and clinical science underlying carotenoid-based nutritional interventions against ocular disease. Prog. Retin. Eye Res. 2016, 50, 34-66. [CrossRef] [PubMed]

44. Vanduchova, A.; Anzenbacher, P.; Anzenbacherova, E. Isothiocyanate from Broccoli, Sulforaphane, and Its Properties. J. Med. Food 2019, 22, 121-126. [CrossRef]

45. Ansary, J.; Forbes-Hernández, T.Y.; Gil, E.; Cianciosi, D.; Zhang, J.; Elexpuru-Zabaleta, M.; Simal-Gandara, J.; Giampieri, F.; Battino, M. Potential Health Benefit of Garlic Based on Human Intervention Studies: A Brief Overview. Antioxidants 2020, 9, 619. [CrossRef] [PubMed]

46. Wan, Q.; Li, N.; Du, L.; Zhao, R.; Yi, M.; Xu, Q.; Zhou, Y. Allium vegetable consumption and health: An umbrella review of meta-analyses of multiple health outcomes. Food Sci. Nutr. 2019, 7, 2451-2470. [CrossRef] [PubMed]

47. Reyes, C.M.; Cornelis, M.C. Caffeine in the Diet: Country-Level Consumption and Guidelines. Nutrients 2018, 10, 1772. [CrossRef] [PubMed]

48. McCusker, R.R.; Goldberger, B.A.; Cone, E.J. Caffeine content of specialty coffees. J. Anal. Toxicol. 2003, 27, 520-522. [CrossRef] [PubMed]

49. Gonzalez de Mejia, E.; Ramirez-Mares, M.V. Impact of caffeine and coffee on our health. Trends Endocrinol. Metab. 2014, 25, 489-492. [CrossRef] [PubMed] 
50. Hursel, R.; Viechtbauer, W.; Dulloo, A.G.; Tremblay, A.; Tappy, L.; Rumpler, W.; Westerterp-Plantenga, M.S. The effects of catechin rich teas and caffeine on energy expenditure and fat oxidation: A meta-analysis. Obes. Rev. 2011, 12, e573-e581. [CrossRef] [PubMed]

51. Wikoff, D.; Welsh, B.T.; Henderson, R.; Brorby, G.P.; Britt, J.; Myers, E.; Goldberger, J.; Lieberman, H.R.; O’Brien, C.; Peck, J.; et al. Systematic review of the potential adverse effects of caffeine consumption in healthy adults, pregnant women, adolescents, and children. Food Chem. Toxicol. 2017, 109, 585-648. [CrossRef] [PubMed]

52. Nawrot, P.; Jordan, S.; Eastwood, J.; Rotstein, J.; Hugenholtz, A.; Feeley, M. Effects of caffeine on human health. Food Addit. Contam. 2003, 20, 1-30. [CrossRef] [PubMed]

53. EFSA. Scientific Opinion on the safety of caffeine. EFSA J. 2015, 13, 4102. Available online: https: / / www.efsa.europa.eu/en/ efsajournal/pub/4102 (accessed on 1 September 2021).

54. Zhu, Q.; Wang, B.; Tan, J.; Liu, T.; Li, L.; Liu, Y.G. Plant Synthetic Metabolic Engineering for Enhancing Crop Nutritional Quality. Plant Commun. 2020, 1, 100017. [CrossRef]

55. Ceccanti, C.; Landi, M.; Benvenuti, S.; Pardossi, A.; Guidi, L. Mediterranean Wild Edible Plants: Weeds or “New Functional Crops"? Molecules 2018, 23, 2299. [CrossRef]

56. Björkman, M.; Klingen, I.; Birch, A.N.; Bones, A.M.; Bruce, T.J.; Johansen, T.J.; Meadow, R.; Mølmann, J.; Seljåsen, R.; Smart, L.E.; et al. Phytochemicals of Brassicaceae in plant protection and human health-Influences of climate, environment and agronomic practice. Phytochemistry 2011, 72, 538-556. [CrossRef]

57. Kesarwani, A.; Chiang, P.Y.; Chen, S.S. Distribution of phenolic compounds and antioxidative activities of rice kernel and their relationships with agronomic practice. Sci. World J. 2014, 2014, 620171. [CrossRef] [PubMed]

58. Palermo, M.; Pellegrini, N.; Fogliano, V. The effect of cooking on the phytochemical content of vegetables. J. Sci. Food Agric. 2014, 94, 1057-1070. [CrossRef] [PubMed] 